\title{
Optimizing operation to increase recovery boiler throughput
}

\author{
F. DONALD MCCABE, DAVID SAVOY, CHRIS HALCROW, AND HONGHI TRAN
}

\begin{abstract}
The recovery boiler at the Irving Pulp and Paper Saint John, NB, mill has been through several major retrofits to increase its original firing capacity of 1100 metric tons/day of black liquor dry solids to the present level of 1680 metric tons/day. Many problems have been encountered over the years, including tube corrosion and cracking, as well as plugging of flue gas passages, but they all have been overcome through operational changes and process optimization. The latest challenge is to increase throughput without experiencing high total reduced sulfur (TRS) levels that would impact the environment and jeopardize compliance. An optimization program has been in place at the mill since December 2008 to further increase boiler production while maintaining environmental performance. The program, which automates liquor addition at full capacity according to targeted stack gas $\mathrm{O}_{2}$ and TRS levels, enables the boiler to operate at lower stack gas $\mathrm{O}_{2}$ targets and to achieve a $2 \%-3 \%$ increase in liquor throughput, while keeping TRS emissions under compliance.
\end{abstract}

Application: Mills that are recovery boiler limited may benefit from this approach for increasing throughput.

rving Pulp and Paper (IPP) is a 1000 a.d. metric ton/ day fully bleached kraft mill located in Saint John, NB, Canada. It processes softwood, maple, and mixed wood species on campaigns of typically 12 days softwood, nine days maple, and five days of mixed production. The mill employs 14 direct steam batch digesters followed by twostage $\mathrm{O}_{2}$ delignification. A conventional five-stage bleach plant uses a conventional D Eop D E D sequence with an original design Single Vessel Process (SVP) that produces $\mathrm{ClO}_{2}$ using methanol based chemistry. Three pulp machines equipped with Flakt dryers bale the pulp product for shipment internally and to the open market. The entire process is controlled by a Honeywell distributed control system (DCS) via two main control rooms, one handling the fiberline and the other controlling both the steam plant and the causticizing plant.

The recovery boiler is a 1970 Babcock \& Wilcox UK boiler originally designed to burn 1100 metric tons/day (2.4 million $\mathrm{lb} /$ day) of as-fired black liquor dry solids (BL d.s.) to support 610 a.d. metric tons/day of pulp production. Over the years, the boiler and the chemical recovery system have undergone several major retrofits, including installation of a new tertiary air system; high solids crystallizer; saltcake purge system; precipitator upgrade; and steam drum internals replacement [1]. These upgrades enabled the mill to increase the as-fired black liquor solids content from $68 \%$ to $72 \%$ in 1996 and then to $74 \%$ in 1997 , as well as substantially increase the boiler firing load. By 2000, the boiler was firing 1680 metric tons/day ( 3.7 million $\mathrm{lb} /$ day) of $\mathrm{BL}$ d.s. at a solids content as high as $76 \%$, and producing up to $260,000 \mathrm{~kg} / \mathrm{hr}(575,000$ $\mathrm{lb} / \mathrm{hr}$ ) steam rated at $440^{\circ} \mathrm{C}\left(825^{\circ} \mathrm{F}\right)$ and 62 bars (900 psig). High pressure steam powers two GE turbogenerators producing a combined $32 \mathrm{MW}$ of generated power.
The recovery boiler has also experienced severe primary air port cracking and widespread membrane bar wastage problems. Despite trying different metallurgies in the lower furnace with two walls and half the floor being $304 \mathrm{~L}$ composite tubes and the other two walls and half the floor made of weld overlaid Inconel 625 tubes, cracking persisted. The problem was found to be strongly related to the frequency and the magnitude of tube temperature excursions at the air ports in the rear left corner of the boiler.

The problems were subsequently alleviated by lowering the black liquor solids content from $76 \%$ to $70 \%$ and by operating at a higher primary air flow rate to keep the char bed away from the air ports. These operational changes significantly reduced tube temperature excursions [2]. However, operating at lower solids and at higher primary air flow rates resulted in lower steam production from the boiler and excessive deposit buildup in the superheater region, which further reduced the boiler efficiency and availability.

In early 2003, a liquor viscosity monitoring and control system was installed to indirectly measure the "viscosity" of as-fired black liquor [3]. The system uses the amperage registered by the black liquor circulation pump to control liquor sprays, char bed size, and firing conditions in the lower furnace. It has been working well, helping to stabilize liquor properties, make char bed control easier, and significantly improve boiler thermal performance, particularly when there is a change in residual alkali or in wood species. It also helps reduce smelt carryover, minimize incidents of tube temperature excursions around primary air ports that caused tube cracking and corrosion, and improve the boiler operation and thermal performance.

The boiler is presently burning in excess of 1725 metric tons/day (3.8 million lb/day) of BL d.s. The latest challenge is 


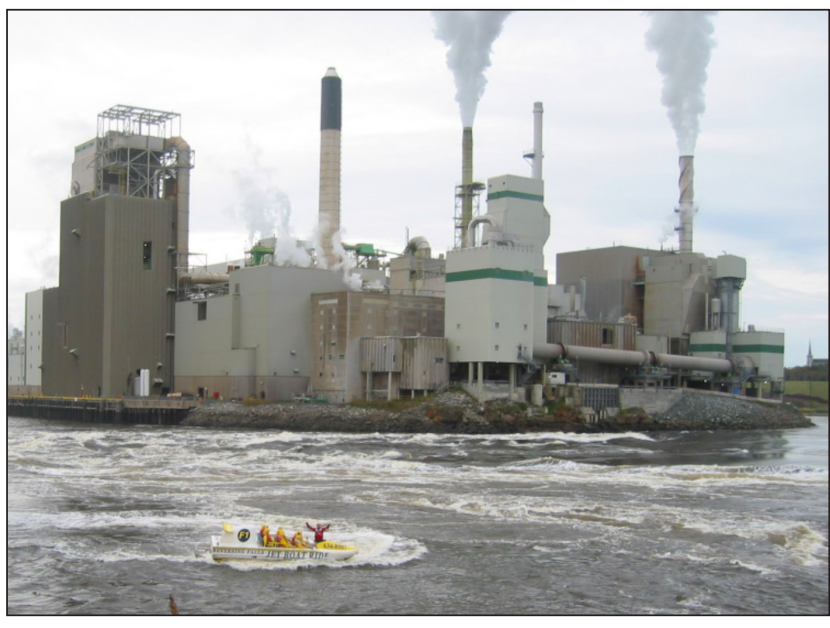

1. Boats rides along the Reversing Falls by the Saint John, NB, mill are a major tourism activity, making TRS emissions an especially sensitive issue.

to increase boiler throughput without increasing TRS emissions that often occur when the boiler is at full load. This is a rather sensitive issue for a mill that is located literally next to a major tourist attraction in Saint John (Figure 1).

In December 2008, an optimization program was put in place at the mill to further increase boiler production while maintaining environmental performance. The program automates the liquor addition at full capacity according to targeted stack gas $\mathrm{O}_{2}$ and TRS levels, enabling the boiler to operate at lower stack gas $\mathrm{O}_{2}$ targets and to achieve a $2 \%-3 \%$ increase in liquor throughput, while keeping TRS emissions under compliance. This paper discusses the principles of the optimization program and results obtained since its implementation.

\section{THE PRINCIPLES}

The recovery boiler is the mill's bottleneck. It is presently operated under a consumed air strategy, which calls for different total air flow targets for different wood-species black liquors. These air flow targets have been chosen to allow the mill to operate for up to seven months at full load without having to reduce throughput due to boiler plugging.

Under the consumed air strategy, the total air flow to the furnace is fixed, while the total liquor flow is varied to achieve a desired stack gas $\mathrm{O}_{2}$ concentration. The liquor flow is then periodically adjusted to maintain the desired $\mathrm{O}_{2}$ and TRS levels in the stack gas. The adjustment is required to accommodate the inherent changes in composition and combustion behavior of the liquor.

At the mill, the recovery boiler operator not only operates the boiler but also the auxiliary equipment to support its operation, including the evaporators, concentrator, high solids crystallizer, Teller scrubber, condensate stripper and condensate handling, and reverse osmosis plant, as well as the demineralizers. Operating experience shows that targeting the stack gas $\mathrm{O}_{2}$ at $1.5 \%$ would allow the operator to run the recovery boiler at high throughputs and the supporting auxiliary equipment at the same time, while still meeting TRS targets. One

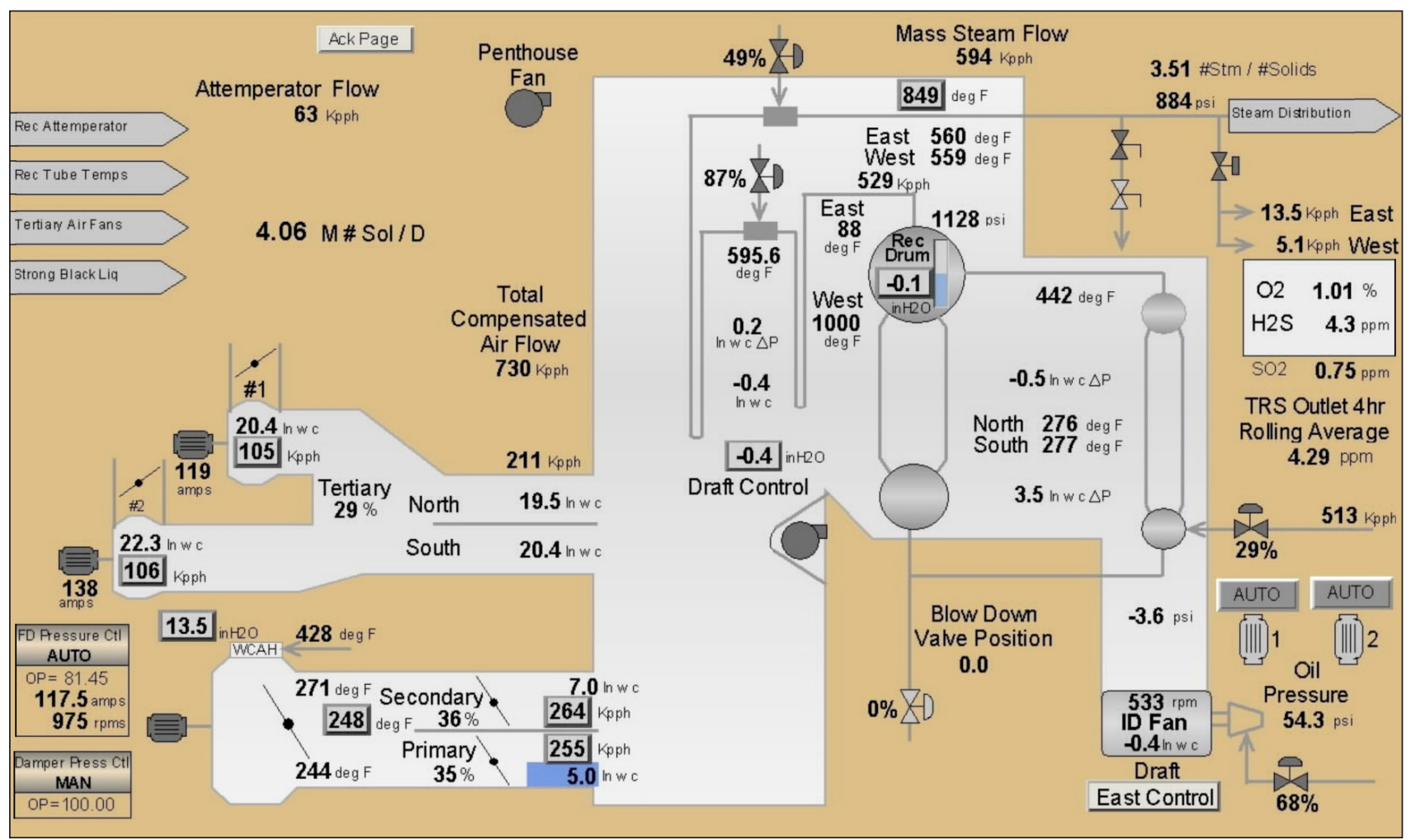

\section{Overview of recovery boiler operating graphic.}




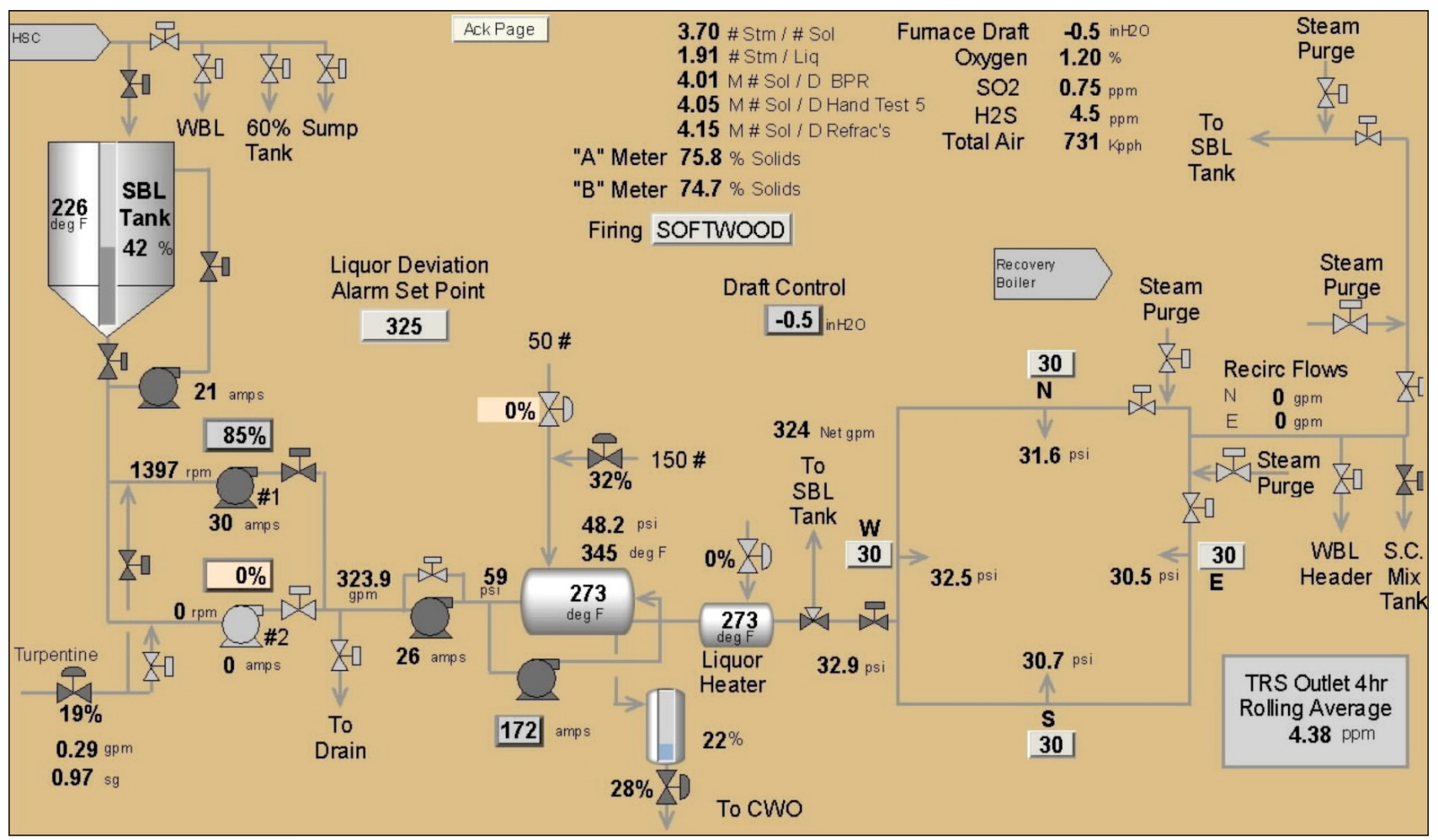

\section{Overview of liquor system operating graphic.}

way to further increase the recovery boiler throughput is to lower the stack gas $\mathrm{O}_{2}$ target by firing more liquor. The risks associated with increased liquor flow are a potential increase in fouling and plugging. Also, a lower $\mathrm{O}_{2}$ target could result in more frequent TRS excursions, which would be problematic given the mill location.

In December 2008, an $\mathrm{O}_{2}$ trim program was incorporated into the Honeywell DCS to closely monitor both $\mathrm{O}_{2}$ and TRS concentrations in the stack gas. When in operation, the program ramps up the liquor flow to the boiler by $1 \mathrm{gal} / \mathrm{min}$ every $10 \mathrm{~min}$ if the $\mathrm{O}_{2}$ content is above a set minimum target and the TRS level is below a set maximum target. Other process variables such as the total steam flow off the drum, liquor gun pressure, and total liquor flow to the furnace must also be kept within a predetermined range. If the $\mathrm{O}_{2}$ content drops too low or if the TRS level exceeds the target, the liquor flow to the furnace will be reduced by 3 gal every 6 min until levels return to below the low and high set limits, respectively. If the other limits are reached (gun pressure, steam off the drum, etc.), then no further increase in liquor flow will be allowed.

In order to avoid a response to fluctuations of $\mathrm{O}_{2}$ and TRS levels that is too fast, the instantaneous values of $\mathrm{O}_{2}$ and TRS are averaged over time periods of $2 \mathrm{~min}, 5 \mathrm{~min}$, and $10 \mathrm{~min}$. It is these averaged values that are used by the program. Each of these averages is compared to predetermined limits. Thus, if any of the $\mathrm{O}_{2}$ averages falls below its target, then the liquor flow to the furnace is ramped down at the rate described in the previous paragraph, as it would be if any of the TRS averages exceeded the upper limits.
The program is designed to operate only when the boiler is fully loaded. Since the mill operates in campaigns, there is a maximum air flow target for each species of black liquor. A dead band of $\pm 10,000 \mathrm{lb} / \mathrm{hr}$ of total air has been put in place to allow for slight variations in air flow. If the total air flow is outside the maximum/minimum air flow, then the program makes no change to the liquor flow. Based on the boiler maximum continuous rating (MCR), a high steam flow limit off the steam drum has been put in place to avoid potential issues with excess sodium carryover in the steam to protect the two steam turbogenerators. Should the steam flow off the drum exceed the maximum, no increases in liquor flow are allowed, even though $\mathrm{O}_{2}$ and TRS limits may be satisfied. The same strategy is applied to gun pressures as a way to avoid a rapid rise/fall in the bed height.

Figure 2 shows the operating graphic used by the recovery boiler operator to operate the air supply to the boiler. The total air flow to the boiler in this case is set for $730,000 \mathrm{lb} / \mathrm{hr}$, which is the maximum rate when firing softwood liquor. The primary, secondary, and tertiary air splits are $35 \%, 36 \%$, and $29 \%$, respectively. Also shown are some key parameters that the $\mathrm{O}_{2}$ trim program uses, such as steam flow $(529,000 \mathrm{lb} / \mathrm{hr})$, stack gas $\mathrm{O}_{2}(1.01 \%)$, and TRS levels ( $4.3 \mathrm{ppm}_{2} \mathrm{~S}$ ). Primary air and secondary air are introduced via an ID fan, while tertiary air is supplied by dedicated fans.

Figure 3 shows the operating graphic used by the recovery boiler operator to control the liquor system. Liquor is supplied by either one of two variable frequency drive (VFD) fuel pumps. The speed of these pumps is controlled according to the desired liquor flow to the furnace, either by a manual input 
from the operator or by the program itself. The liquor subsequently flows through a macerating pump followed by the liquor heating circulating pump, which is part of the black liquor viscosity control system [3]. Also shown are four gun pressures, $\mathrm{O}_{2}$ stack concentration, and $\mathrm{H}_{2} \mathrm{~S}$ stack concentration. All of these values are used by the $\mathrm{O}_{2}$ trim program, plus other key operation variables.

\section{THE PROGRAM}

Figure 4 is an operator display when the $\mathrm{O}_{2}$ trim program is in operation. It consists of six display boxes. The No. 1 box shows the air flow target for each species and the actual air flow rate, in $1000 \mathrm{lb} / \mathrm{hr}$. The actual air flow appears adjacent to the species of liquor that is being burned. In this display, the liquor that is burning is maple.

The No. 2 box shows safety checks the program makes before allowing a liquor change. In this case, the total liquor flow to the boiler must be between 280 and $340 \mathrm{gal} / \mathrm{min}$. The program will make a change to the liquor flow only within this range. Similarly, the liquor gun pressures must be between 28 and $36 \mathrm{psig}$ in order for the program to make a change in liquor flow. An upper limit for the steam flow is also checked for reasons explained previously. Current values are also displayed. If they are outside the limits, they are displayed in red.

The No. 3 box displays the $2 \mathrm{~min}, 5 \mathrm{~min}$, and $10 \mathrm{~min}$ high and low average limits that must be met to allow ramping up, as well the high and low limits that trigger ramping down of the liquor flow. Current (actual) values are also displayed.

The No. 4 box shows the ramping rates. In this case, the $\mathrm{O}_{2}$ trim program will add $1 \mathrm{gal} / \mathrm{min}$ of liquor every $10 \mathrm{~min}$, given that the previously mentioned limits are not exceeded. If the limits are exceeded (for example, if the $2 \mathrm{~min}$ TRS average is higher than $7.5 \mathrm{ppm}$ ), then $3 \mathrm{gal} / \mathrm{min}$ of liquor will be removed every 6 min until the TRS value drops below $7.5 \mathrm{ppm}$.

The No. 5 box displays the number of conditions that must be met in order for ramping to occur. The program is configured to allow ramping up or down if one, two, or three conditions from the $\mathrm{O}_{2}$ /TRS limits are met. In this case if any one of the limits is not met, then no ramping is allowed. The No. 6 box indicates which VFD fuel pump is in use and whether the program is in operation.

Figure 5 shows the logic flow diagram that the program executes once per minute.

\section{RESULTS AND DISCUSSION}

\section{$\mathrm{O}_{2}$ trim operations}

Under steady state conditions, the $\mathrm{O}_{2}$ trim program continually pushes the boiler to operate at or near its defined $\mathrm{O}_{2}$ and TRS limits. Figure $\mathbf{6}$ shows a typical trend under steady state conditions of the recovery boiler over a 3 -h period on November 29, 2009. The black liquor firing load (red and pink trends) was ramped up until the stack $\mathrm{O}_{2}$ (blue trend) was reduced sufficiently to cause a TRS spike in the recovery exit gas (black

\section{Recovery Boiler Load Optimization}

\begin{tabular}{|lccc|}
\hline \multicolumn{5}{c|}{ Air Flows } \\
Softwood & Target & Actual \\
Maple & 730 & & \\
Mixed & 668 & 667 & \\
\hline \multicolumn{5}{|c|}{ Paramaters } \\
& 630 & & \\
\hline \multicolumn{5}{c}{ Max } & Min & Actual \\
Flow & 340 & 280 & 308 \\
ressure & 36.0 & 28.0 & 33.0 \\
Steam Flow & 530 & & 502 \\
\hline
\end{tabular}

limits

Limits

Limit Actual Low Limit

1.00
1.05

1.28

0.95

0.95
1.00

7.50

10.50

16.50

2.94
4

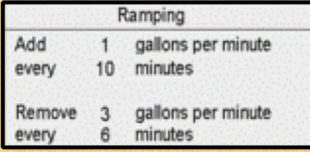

5

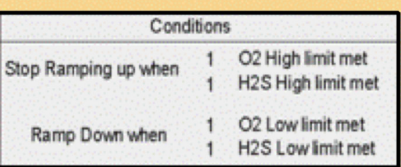

6

\begin{tabular}{l}
\hline \multicolumn{1}{|c|}{ Pumps } \\
Fuel Pump \#1 is Stopped \\
\#1 BL Flowto fumace is Not in Program \\
Fuel Pump \#2 is Running \\
$\$ 2$ BL. Flowto fumace is in Program
\end{tabular}

4. Operating graphic used by Saint John mill operators to
monitor the $\mathrm{O}_{2}$ trim program and recovery boiler conditions.

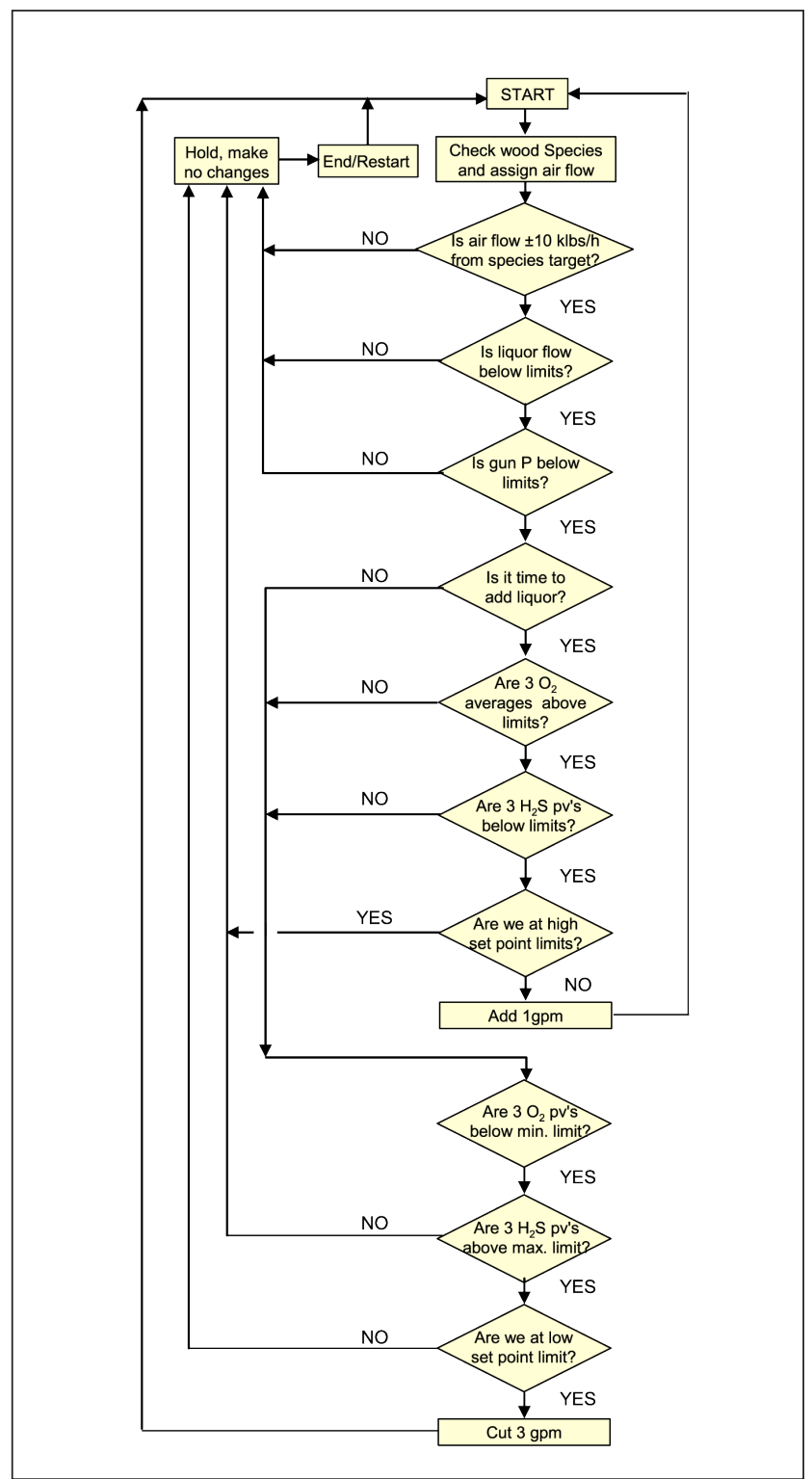

5. Logic flow diagram of the $\mathrm{O}_{2}$ trim package. 


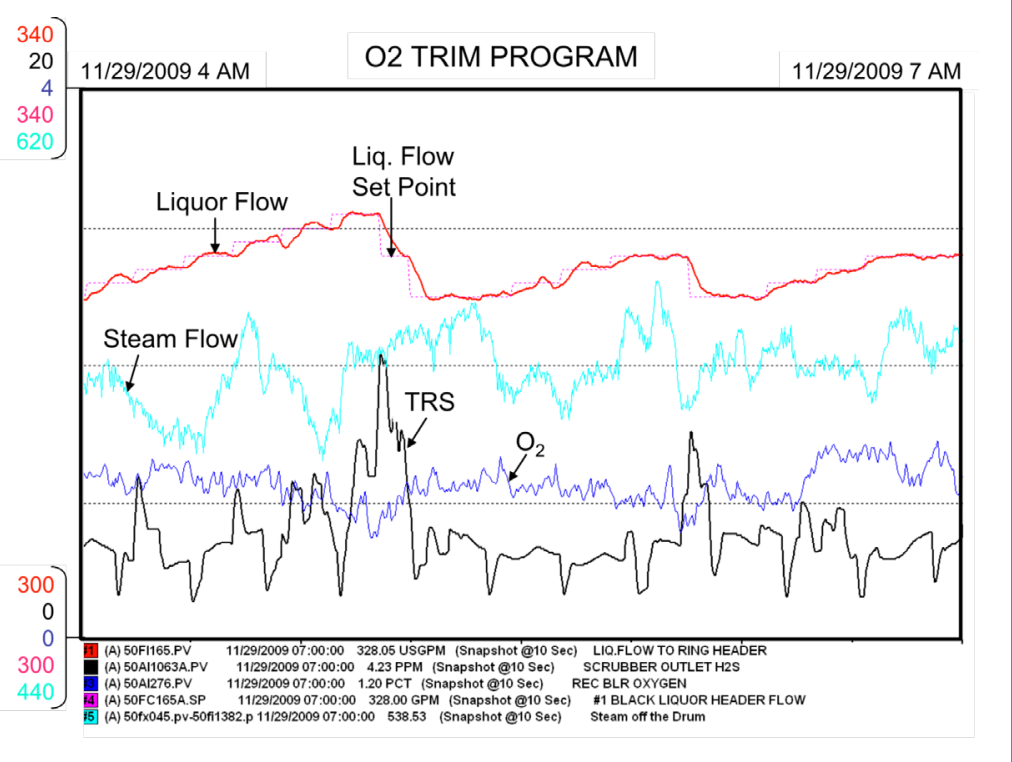

6. Trends of key recovery boiler variables during a 3-h $\mathrm{O}_{2}$ trim program operation from 4AM to 7AM on November 29, 2009.

trend). This prompted an immediate black liquor reduction, followed by another ramp up until TRS levels allowed further increases. The second and third plateaus were caused when the final steam flow rate (cyan trend) exceeded its limit of $530,000 \mathrm{lb} / \mathrm{hr}$. When this happens, no further increases are allowed. Liquor reductions are allowed only when either a high TRS limit or low $\mathrm{O}_{2}$ limit is exceeded.

Figure 7 shows similar results. These examples clearly suggest that the $\mathrm{O} 2$ trim program works well, allowing the boiler to operate at the highest possible firing load while keeping TRS emissions under compliance.

\section{Performance Analysis}

A series of runs for both softwood and hardwood were analyzed over a two year period (one year before and one year after the $\mathrm{O}_{2}$ trim program was installed). For each run, the recovery boiler was fully loaded for at least 4 days in a row. As Fig. 8 shows, the $\mathrm{O}_{2}$ trim program allowed the boiler to operate at a lower stack gas $\mathrm{O}_{2}$ content of $1.2 \%$, compared with $1.5 \%$ before the program's installation. Since both wood species use the same consumed air strategy, albeit different air targets, more solids were fired when the program was in operation. The average firing load on softwood increased from 3.91 to 4.01 million lb/day, representing a throughput increase of $2.6 \%$.

The steam production decreased slightly $-1.5 \%$ - from $3.18 \mathrm{lb}$ steam/lb BL d.s. before to $3.13 \mathrm{lb}$ steam/lb BL d.s. after the $\mathrm{O}_{2}$ trim program was put in place. Note, however, that the steam production shown in this figure did not include attemperator
RECOVERY BOILER

flow, which was substantially higher after the implementation of the $\mathrm{O}_{2}$ trim program. If the increase in attemperator flow is taken into account, there is virtually no change in total steam production. Similar results were obtained during hardwood runs, although the number and length of runs were fewer and shorter.

In addition to the gains made on the boiler, TRS emissions remain low, which is vital since the mill is located in the middle of a tourist attraction near the city center. Since the inception of the $\mathrm{O}_{2}$ trim program, the mill has not received one public complaint attributed to TRS emissions from the recovery boilers.

It is important to note that constantly adjusting the liquor flow to the furnace can lead to unstable operation in the lower furnace, as well as increased carryover and fouling/plugging rates, in an already heavily loaded boiler. This, however, has not been the case. The boiler averaged 576 days between major mill shutdowns (including two water washes) prior to the program, and 565 days to the next major mill shutdown (including two water washes) after the program was put into operation. Visual inspections prior to waterwashes have not seen an increase in pluggage. Atttemporating rates just prior to a water wash or shutdown (an indicator of fouling in the superheater) have actually increased from $29,000 \mathrm{lb} / \mathrm{hr}$ to more than $40,000 \mathrm{lb} / \mathrm{hr}$. Another process indicator of fouling is the economizer gas exit temperature, which has remained below $500^{\circ} \mathrm{F}$ for both pre- and post-program.

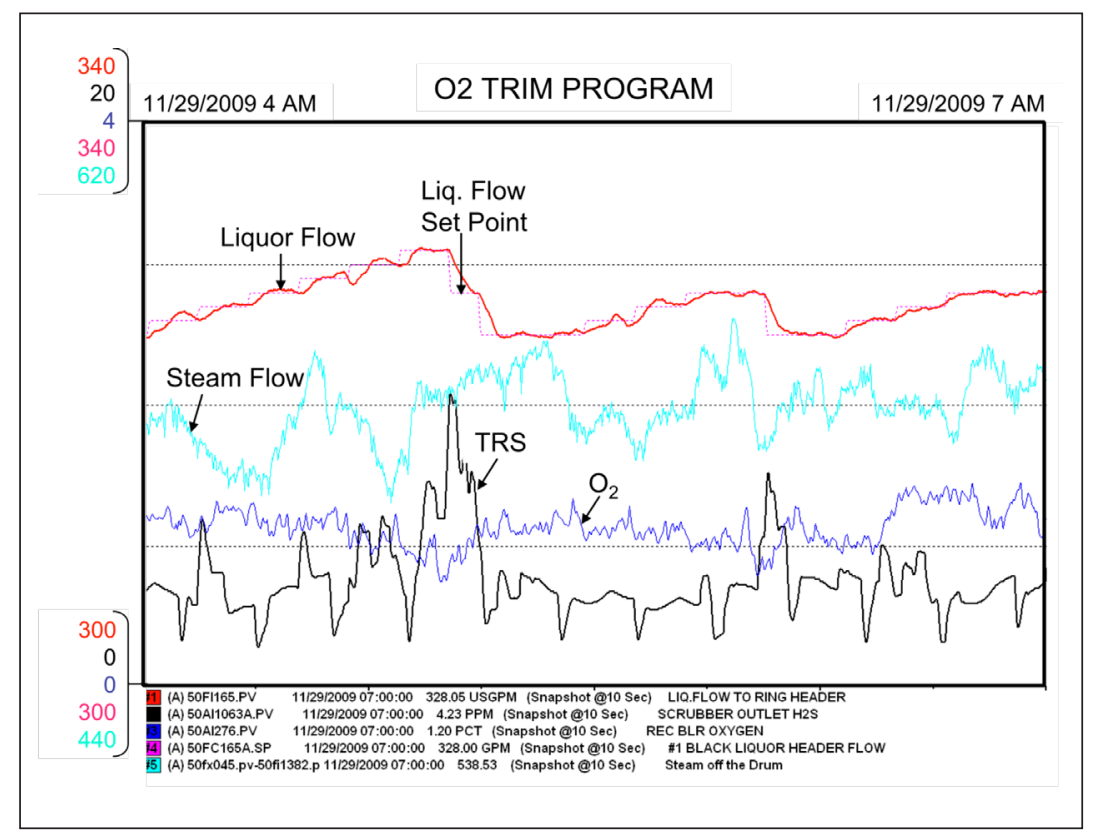

7. Trends of key recovery boiler variables during a 3-h $\mathrm{O}_{2}$ trim program operation from 7AM to 10AM on June 14, 2009. 


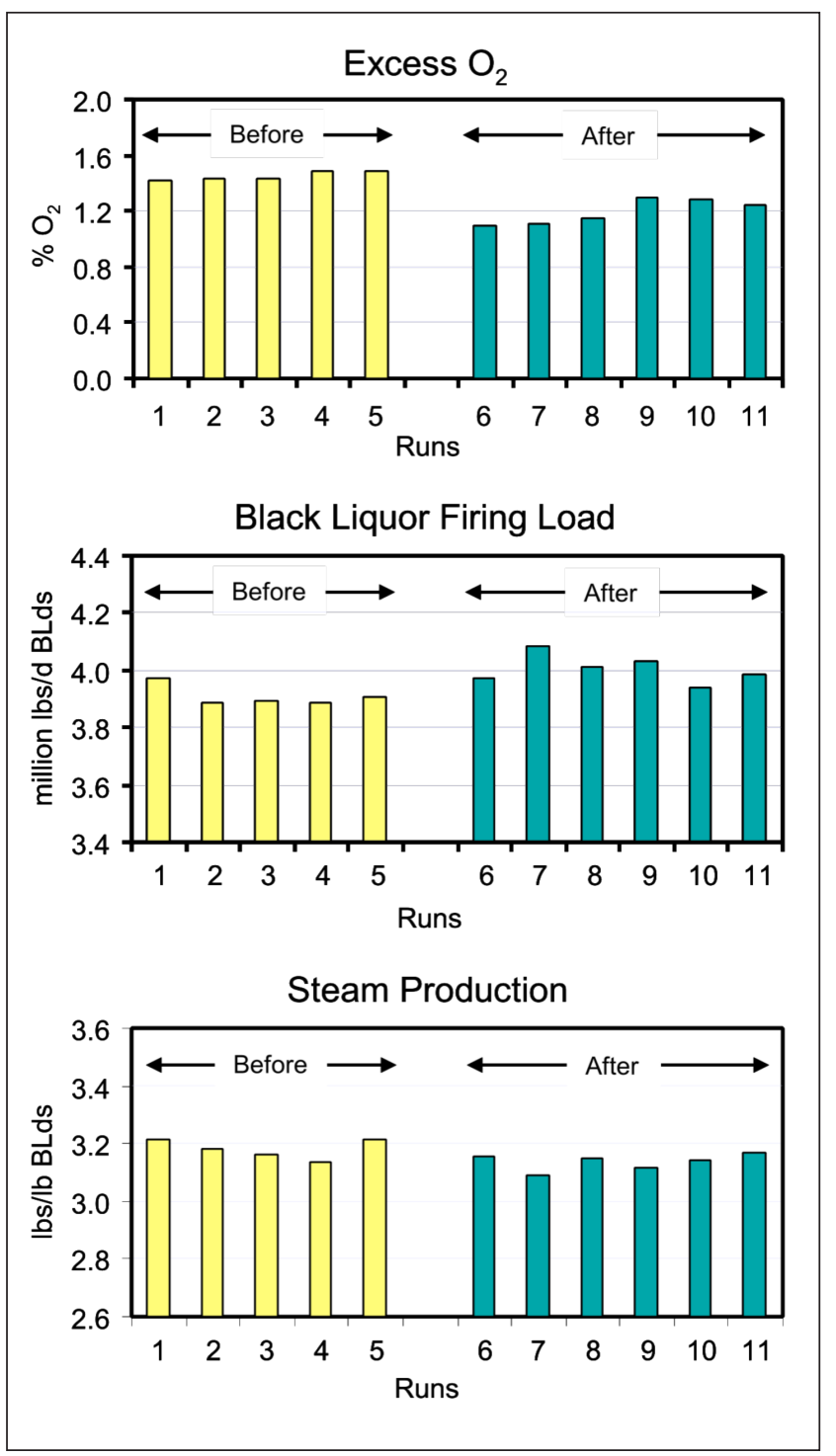

8. Excess $\mathrm{O}_{2}$, black liquor firing load and steam production during softwood runs before and after implementation of the $\mathrm{O}_{2}$ trim program.

\section{CONCLUSIONS}

The implementation of the $\mathrm{O}_{2}$ trim program is the latest step in a long series of recovery boiler optimization efforts at Saint John. With the heavily loaded boiler operating under a consumed air strategy, this simple in-house program is viable to the boiler operation. The program constantly maximizes liquor firing while maintaining a quick response to environmental emissions.

Thanks to the program, the increased black liquor throughput has not resulted in increased TRS emissions. No public odor complaints have been received to date. The initial fear of many small liquor adjustments leading to increased plugging has not been seen. Further optimization involving modifying ramp rates and frequency are planned so that the dwell time at lower liquor flows to the furnace are minimized. TJ

\section{LITERATURE CITED}

1. Mackenzie, C.M., Hiner, L., Wessel, R., et al., TAPPI Eng. Conf., TAPPI Press, Atlanta, 1997, pp. 1365-1394.

2. Tran, H.N., Vafa, S., Milbury, C., et al., TAPPI J. 2(12): 9(2003)

3. McCabe, D.F., Mott, D., Savoy, D., et al., Pulp Pap. Can. 108(5): 43(2007)

\section{ABOUT THE AUTHORS}

We chose to research the recovery boiler as it is our mill's bottleneck and research could potentially lead to an increase in throughput at minimal cost. Previous work had been done on primary air port cracking and reclaiming boiler efficiency at the mill, so this program was a logical next step for increasing production.

The most difficult aspect of the work was the potential for increased boiler plugging due to increased firing load. We addressed this by constantly monitoring boiler operation.

In the end, we were surprised at how much throughput was gained at little expense. For the future, we plan some minor tuning adjustments that may further increase boiler throughput.

McCabe is senior process engineer, Savoy is CRU operations/ maintenance coordinator, and Halcrow is process pulping superintendent at Irving Pulp and Paper, Saint John, NB, Canada. Tran is professor at the Pulp \& Paper Center, University of Toronto, Toronto, ON. Email Tran at honghi.tran@utoronto.ca.

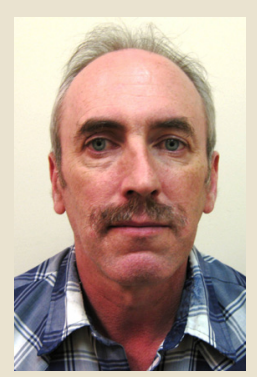

McCabe

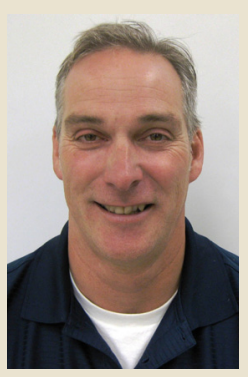

Savoy

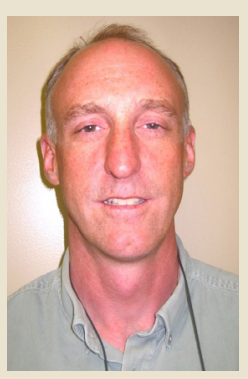

Halcrow

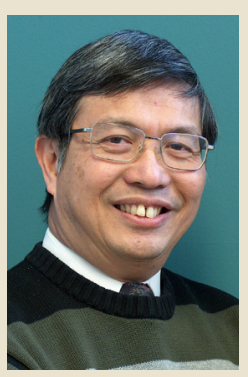

Tran 